\title{
A Review Paper on Graphene Coated Fibres
}

\author{
Deepak Gadakh, Pratik Dashora, Gaurav Wadhankar \\ Manufacturing Department, Birla Institute of Technology and Science, Pilani, India \\ Email: deepakstmg@gmail.com
}

How to cite this paper: Gadakh, D., Dashora, P. and Wadhankar, G. (2019) A Review Paper on Graphene Coated Fibres. Graphene, 8, 53-74.

https://doi.org/10.4236/graphene.2019.84004

Received: October 1, 2019

Accepted: October 27, 2019

Published: October 30, 2019

Copyright $\odot 2019$ by author(s) and Scientific Research Publishing Inc. This work is licensed under the Creative Commons Attribution International License (CC BY 4.0).

http://creativecommons.org/licenses/by/4.0/

\begin{abstract}
Graphene is now known as a super material because of its fascinating physical properties. Due to a great scope of research, it has now become a center of attraction of research scholars in physics, chemistry as well as materials science to study and explore its potential applications. In this paper, a brief review is presented on the various graphene synthesis methods and a short introduction of different types of fibres is discussed. Various studies have been carried out to obtain graphene coating on different fibres and observe the changes in their physical and chemical properties. This paper also provides the different types of coating methods used to form graphene layer on the fibres discussed.
\end{abstract}

\section{Keywords}

Graphene, Carbon Fiber, Natural Fiber, Organic Fibres, Fibers

\section{Introduction}

Graphene, a material of new generation, is a carbon allotrop that was first isolated in 2004 by simple mechanical exfoliation. This is a two-dimensional honey comb of single-layer crystal lattice, formed by the tightly packed carbon atoms bonded to sp2. Because of the unique graphene structure, these carbon atoms form an excellent carrier space for electrons [1]. Graphene has remarkable electrical properties such as strong room temperature electron mobility and room temperature ballistic and quantum hall effect [2]. Moreover, graphene has excellent optical properties as well. Excellent mechanical properties i.e. $130 \mathrm{GPa}$ tensile strength and 1TPa Young's Modulus, have been identified and the mechanical properties effected with the amount of graphene layers and inner graphene layer defects. Because of the excellent graphene properties, it is believed that it could be used to significantly improve the coating performance [3]. Coating is usually used to enhance a substrate's surface properties, wettability, corrosion 
resistance and adhesion [4].

The coating industry has been driven by economic benefits and growing environmental concerns to seek new technologies and materials to improve the efficiency of coatings. There are several factors affecting the efficacy of a coating against all possible harmful sources: the quality of the coating, the characteristics of the substratum, the characteristics of the coating/substrate interface, and the corrosiveness of the environment [5]. With increase of industrial requirement, a nanocomposites polymer have been investigated highly and applied in coating. As nanocomposite provide superior properties with relative low cost. The manufacturing process can also be much less complex than multi-layer coatings [6].

Over the past few years, incorporation of graphene or graphene oxide (GO) sheets has been reported on a wide range of polymer matrix. Graphene is identified as a high water and oil repellent material while Graphene Oxide (GO) is hydrophilic [7]. In process of achieving optimum enhancement in mechanical properties of polymer matrix composites, there are many numbers of key issues should be fixed, i.e., Graphene dispersion and alignment in polymer and graphene surface modification for favorable interaction [8]. It is well known, Graphene synthesis formed in a wrapped structure and interlaminar van der Waal forces promotes graphene sheet agglomeration. However, the dispersion and exfoliation of graphene in media, when combined with polymer, is a major obstacle. Graphene sheet's poor dispersion and agglomeration created nano defects in laminated composites that cause only minimal mechanical enhancement properties [9].

In this paper, an effective method of depositing graphene oxide onto the different fibres is proposed. The Graphene or graphene oxide is introduced onto fibres which improved there mechanical and electrical properties [10]. Tensile and compressive testing have to done onto the fabrication, also SEM testing can be done to see the layers delamination. There have been reports of good frictional properties and high wear resistance. These results mean that graphene can become a protective coating to against scratch or other physical damage [11] [12]. Graphene has also been shown to be an effective barrier material for corrosion as it was considered inert under the conditions under which chemical reactions from other substrates occur. As a result, the improvement of the anti-corrosion properties of a coating system can be promised [12].

Graphene is thought to be promising in coating applications, but the articles intended for coating applications are limited. The methods of graphene synthesis and functionalization were briefly described in this review.

\section{Synthesis of Graphene}

Single layer graphene was first produced in reproducible manner in year 2004. Graphene was prepared by mechanical peeing off graphite. There are two method for producing graphene one is bottom-up and other top-down [13]. Bottom-up 
method is growth of graphene with precise control of layers. This method is more costly and used in high end electronics, printed circuit boards, solar cells. In top-up method extraction of graphene layer by layer is done from bulk graphite. This method is used in mass production and have low production cost [14].

Graphene produced by above methods have low quantity and high production compare to graphene oxide production. It has also been widely studied with CNTs and other graphene compounds, but poor dispersion properties and weak bonding have resulted in less use of these compounds, with GO having broad surface area in particular, high dispersion potential in polar solvents. Graphene oxide preparation is simpler than graphene and less costly which is added advantage [15]. Many chemical groups such as carboxyl (-COOH) carbonyl $\left(-\mathrm{NH}_{2}\right)$ hydroxyl group $(-\mathrm{OH})$ are present at end of GO sheet which makes GO more reactive [16].

\subsection{CVD}

CVD is the most effective method used for the production of graphene however it requires some special equipment The CVD process typically involves two steps: the first step is the one in which the gaseous reactants are activated and pyrolysis is done so that the carbon atom disassociate [17]. Also this must be carried on the surface of the substrate since it should not form precipitation of carbon soot (cluster) during this gaseous phase. In the second step reaction a solid deposit which is in stable state is formed over a suitable substrate with the help of chemical reaction. This step requires a large temperature of around $2500^{\circ} \mathrm{C}$, in order to overcome this problem a catalyst is used since it will reduce the temperature to greater extent to around $900^{\circ} \mathrm{C}$ which is required for reaction. There are two types of reactions in the deposition process: homogeneous reactions in the gaseous phase and heterogeneous chemical reactions that occur on a heated surface [18]. So, CVD method basically makes use of a carbon source that decomposes in the high-temperature reaction zone which subsequently results in the formation of graphene membrane by releasing carbon atoms in the substrate [19].

The CVD method is divided into various forms like thermal CVD and plasma CVD etc. However the modern methods in CVD can be distinguished on basis of deposition of operating pressure. The two main types are LPCVD and UHVCVD. LPCVD is a low pressure CVD method in which the operating pressure is under sub atmospheric pressure. UHVCVD i.e. ultra high vacuum CVD in which operating pressure is extremely low i.e. about $10^{-6}$ pascals [20]. Operating under low pressure helps in prevention of unnecessary reaction and uniform thickness formation on the substrate. The outcome of graphene synthesis using CVD method depends on several factors, such as temperature, strain, volume of gas, and length of time. The problems faced in this method is when catalyst is used it becomes it part of reaction chamber, hence effecting the reaction [20]. Another major problem is creating uniform layer of graphene on the substrate due to constant changes in diffusion and convection values which had 
effect on chemical reaction. The advantage CVD method is that it produces graphene on a large scale and of high quality. The major disadvantage of this method is it is costly due to requirement of special equipment [18] [19] [20].

\subsection{Epitaxial Growth on Substrates}

Epitaxial growth is highly acclaimed and governable method in synthesis of graphene. The word epitaxy is derived from the combination of two Greek words "epi" and "taxis". The first word "epi" means upon and over while "taxis" means arrangement or an ordered manner [21]. Epitaxy refers to a method of crystal growth or deposition of material in which new crystalline layers are produced with a well-defined orientation towards the crystalline substratum. The formation of the new layers is called the epitaxial film or epitaxial layer [21] [22]. This highly controllable process is desorption of atom from the surface of annealed substrate i.e. $\mathrm{SiC}$ in this case. The deposition of graphite on semiconducting substrates $(\mathrm{SiC})$ by epitaxial growth method was known since 1975. Berger and his coworkers successfully demonstrated that epitaxial graphene sheet can be synthesized by using $\mathrm{Si}$ terminated face of single-crystal $6 \mathrm{H}-\mathrm{SiC}$ by thermal desorption of Si. In other words, graphene with single crystal structure can be produced epitaxially at $\mathrm{SiC}$, by controlling the annealing temperature and time [23]. Moreover, the number of atomic layers of graphene can also be controlled by this process.

The epitaxial growth of graphene can be divided into two types based on the type of substrate used they are homo epitaxial growth and hetero epitaxial growth. The homo epitaxial growth is one in which the film deposited is of same substance as that of the substrate. While in case of hetero epitaxial growth the film deposited on the substrate is of different material. The problem associated with the process is high operating temperature. Another major problem is it cannot be transferred on the surface of any other substrate. The advantage of this process is it produces very large of high quality graphene but at very small scale. The main drawback of the process is that it is expensive [24] [25]. The process is performed in vacuum condition but advancement in the process can be done performing growth in Ar environment which helps in improving the quality of graphene.

\subsection{Reduced Graphene Oxide (rG0)}

\section{By Hummers Method}

Chemical reduction of graphene oxide is a traditional method for preparation of graphene on a large scale. In this method, first, the oxidation of graphite is carried out by treating it with $\mathrm{KMnO}_{4}, \mathrm{NaNO}_{3}$, and so on. In the second step, the preparation of GO is done from flake graphite which can be used to make a uniformly dispersed suspension in water as GO is hydrophilic in nature [26]. This suspension can be treated with reducing agents to get reduced graphene oxide. $\mathrm{NaBH}_{4}$ has been used as reducing agent to greater extent. Different reducing used are hyrdrazine, pyrrole, glucose, alkaline acid etc [26]. The advantage of 
this process is un-oxidized sheets are formed. But the main drawback is that it would result defects in graphene.

\subsection{Mechanical Exfoliation}

Mechanical exfoliation is one of the simplest method for production of graphene. The first graphene layer was prepared using this method. So this became most widely used method for preparation of graphene. In this process mechanical force application is used to strip the graphene layers from the graphite crystal surface. In other words the graphene layers are peeled off from the surface of graphite using mechanical exfoliation. Various agents used for thus peeling off or exfoliation technique is scotch tape, printing technique etc [27]. Although this is very simple method but it has very low efficiency. Efoorts have been put to improve the method of mechanical exfoliation. One way is when peeled off multiple layers are present on tape. Then it is exfoliated repetitively to reduce the number of layer and form a fine layer of graphene [28]. This method is called as micromechanical exfoliation.

To improve the quality of the graphene produced the process is modified using solvents and surfactants. Nonetheless, this usage is limited due to difficulties in the deposition of graphene due to the high boiling point of solvent and also the related costs of solvent are high. The major advantage is high quality graphene sheets can be prepared from mechanical exfoliation technique. Also it is by far the cheapest method in synthesis of graphene [29]. The main drawback of this method is that there is a difficulty in controlling the size and number of layers. Because of these difficulties this method is not used for mass production.

\subsection{Liquid-Phase Exfoliation}

Sonication process is used to obtain graphene from graphite in solvents in liquid-phase exfoliation. Layers of graphene is present in graphite which are held together by Vander Waals forces [30]. These forces can be overcome if the solvent having surface tension near $40-50 \mathrm{~mJ} / \mathrm{m}^{2}$ range are used for example DMF (N,N-Dimethylformamide) and ODCB (ortho-dichlorobenzene). Generally, $2 \mathrm{~g}$ graphite powder is added to $300 \mathrm{ml}$ of ODCB. Then sonication is done for $3 \mathrm{~h}$ after this centrifuged for $30 \mathrm{~min}$ at $4000 \mathrm{rpm}$ (Figure 1). Finally the liquid lying above the solid residue is used for characterization by using SEM and TEM. The operating conditions for this are quite normal as it does not require vacuum condition and high temperature [31].

\subsection{Electro-Chemical Exfoliation}

Electro-chemical exfoliation is an alternative to the mechanical exfoliation for the synthesis of graphene from graphite. It is two step process in which at first, the van der Waals interlayer forces to maximize the spacing of the interlayer. It thus forms compounds intercalated with graphene. Instead, through rapid heating or sonication, this exfoliates graphene with single to few layers [32]. 


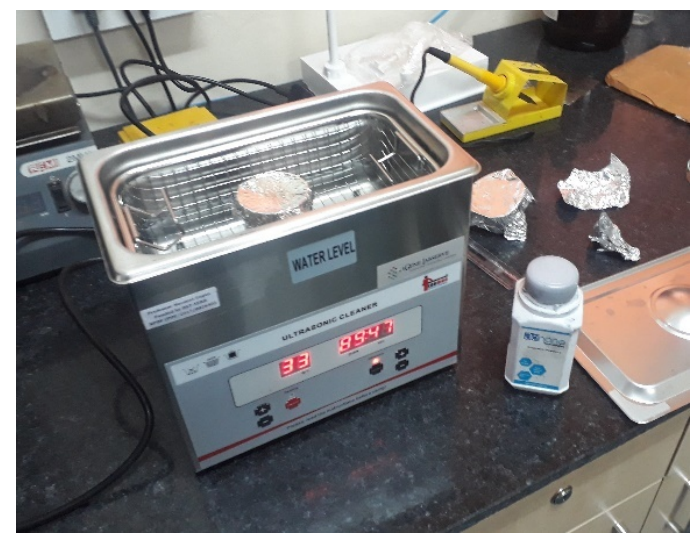

Figure 1. Sonification.

The graphite served as an anode once the potential of $+10 \mathrm{~V}$ was set on it. Thus, the graphite itself played the role of anode while a platinum plate worked as the cathode, ground potential is set on it. The $1 \mathrm{M}$ solution of water with $\mathrm{Na}_{2} \mathrm{SO}_{4}$ is used as electrolyte. After this all platinum electrodes and graphite foil residues are extracted and the suspension has salt, electrolyte residues, exfoliated graphene flakes, graphite residues are poured into a beaker and other chemical manipulations are subjected. Spectacular exfoliation of the foil is observed after only a few minutes, i.e., loose black flakes split from the foil, forming a dark suspension while the foil electrode itself vanished gradually [33]. A direct current (DC) voltage is applied between the platinum and graphite electrodes, and the electrolysis procedure lasted $2 \mathrm{~h}$ for graphite powder and $30 \mathrm{~min}$ for graphite foil at room temperature. During this process, substances expected to work as a separator of newly exfoliated graphene flakesare added in one of two forms: a nano-powder of $\mathrm{CaCO}_{3}\left(5-40 \mathrm{~nm}\right.$ diameter) or a saturated solution of $\mathrm{Na}_{2} \mathrm{CO}_{3}$ [33] [34].

Graphene flakes obtained through electrochemical graphite split are durably separated by the use of an additional agent, (nano-grains of $\mathrm{Na}_{2} \mathrm{CO}_{3}$ or $\mathrm{CaCO}_{3}$ ). Furfuryl alcohol is added along with $\mathrm{H}_{3} \mathrm{PO}_{4}$ (polycondensation catalyst) as a potential gluing agent. The resulting graphene-furfuryl alcohol mass is subjected to heat treatment to polymerize PA to poly (furfuryl alcohol (PFA) $\left(1 \mathrm{~h}\right.$ at $\left.100^{\circ} \mathrm{C}\right)$, then carbonized in a $\mathrm{N}_{2}$ atmosphere with a heating rate of $10^{\circ} \mathrm{C} \cdot \mathrm{min}^{-1}$ up to $600^{\circ} \mathrm{C}$. This temperature is maintained for $1 \mathrm{~h}$. After carbonization, the samples are treated with a concentrated $(34 \%-37 \%) \mathrm{HCl}$ solution for $20 \mathrm{~min}(12 \mathrm{ml}$ of acid was used per $1 \mathrm{~g}$ of carbon) to remove $\mathrm{Na}_{2} \mathrm{CO}_{3}$ or $\mathrm{CaCO}_{3}$. Then wash with distilled water till $\mathrm{PH}$ reach 6 - 7. Dried in furnace $100^{\circ} \mathrm{C}$ for $24 \mathrm{~h}$. Denote different name, the sample obtained from $\mathrm{Na}_{2} \mathrm{CO}_{3}$ and $\mathrm{CaCO}_{3}$ [35].

\section{Types of Fibres}

\subsection{Carbon Fibre}

Carbon fibers or carbon fibers (alternatively CF) are fibers with a diameter of around $5-10 \mathrm{~mm}$ and consist primarily of carbon atoms. High tensile strength, 
high rigidity, low weight, low thermal expansion, high chemical resistance and high temperature tolerance [36]. Carbon fibre is made by, bonding carbon atom together in crystals that are somewhat aligned in parallel to the long axis of the fibre. This alignment of crystals gives the fibre high strength-to-volume ratio. Several thousand carbon fibres are combined to form a tow that can be used alone or woven into a fabric [37]. Carbon fibres may used combined with other materials to form a composite. E.g., When impregnated with a plastic resin and baked it forms carbon-fibre-reinforced polymer which has a very high strengthto-weight ratio, and is extremely rigid and also somewhat brittle [38]. Many of these properties, carbon fiber is used along with other professional sports in aerospace, civil engineering, military, and motor sports.

The carbon fibre's atomic structure is similar to that of graphite, composed of carbon atom sheets organized in a regular hexagonal pattern (graphene sheets), the difference being in the way these is sheets interlock. Graphite is a crystalline material in which the sheets are stacked parallel to one another in regular fashion [39] [40]. The intermolecular forces between the sheets are relatively weak Van der Waals forces, giving graphite its brittle and soft characteristics.

Carbon fibre may be turbostratic or graphitic, or can have a hybrid structure with both turbostratic and graphitic parts present, depending on process of making fibre. Carbon fibres made from polyacrylonitrile (PAN) are turbostratic, whereas carbon fibres made from mesophase pitch are graphitic after heat treatment at temperatures over $2200^{\circ} \mathrm{C}$ [41]. The Sheets of carbon atoms are haphazardly folded, or crumpled, together in turbostraticfibre.

\subsubsection{Types of Carbon Fibre \\ PAN Type}

A type of the fibre, produced by carbonization of PAN precursor (PAN: Polyacrylonitrile), having high tensile strength and high elastic modulus, extensively applied for structural material composites in aerospace and industrial field and sporting/recreational goods.

\section{Pitch Type}

Type of the fibre, produced by carbonization of oil/coal pitch precursor, having extensive properties from high elastic modlus to low elastic modlus. Fibres with high elastic modulus are extensively adopted in high stiffness components and various uses as utilizing high thermal conductivity and/or electric conductivity.

\subsubsection{Applications of Carbon Fibre}

Carbon fibre may be more costly than other fabrics which are one of the limiting factors for adoption. In a comparison between carbon fibre and steel materials for automotive materials, carbon fibre cost may be 10 - 12 times more expensive. However, this cost has gone down over the past decade from estimates of 35 times more expensive than steel in the early $2000 \mathrm{~s}$.

Composites material

Composed of carbon fiber-reinforced graphite, reinforced carbon-carbon 
(RCC) is used in high-temperature applications. Carbon fibre can be used as an asphalt additive to render asphalt concrete which is electrically conductive. This composite material can be used in the transportation infrastructure, especially for airport pavement, decreases some winter maintenance problems [42].

\section{Textile}

Carbon fibre filament yarns are used in several processing techniques, one of the use is filament winding, prepregging, pultrusion, braiding, weaving etc. Carbon fibre yarn is rated based on the linear density or by number of filaments per yarn count [43].

\section{Microelectrode}

Carbon-fibre microelectrodes are used either in fast-scan cyclic voltammetry or amperometry for detection of biochemical signaling.

Flexible heating

Carbon fibres have the ability of carrying low currents on their own. They can be used to reliably deliver infrared heating, if woven into larger fabrics.

\subsection{Glass Fibre}

Glass is the oldest, and most known, fibre. Fibres are being made from glass long back from the 1930s. Glass fibre is also known as fibreglass. The fibreglass is a lightweight, solid and durable substance constructed from extremely fine glass fibres. The strength properties are much smaller than carbon fibre as compared with carbon fibre. But on the other hand it is less stiff and far less brittle, and in addition to it the raw materials are much less costly [44]. The bulk strength and weight properties of glass fibres when compared to metals are also good enough.

\subsubsection{Types of Glass Fibre}

The glass fibre is classified into following:

$A$-glass: A-glass is known for its resistance to chemicals and are also called as alkali glass. If composition is taken into consideration, it is close to window glass. Process equipments are made from this type of glass in some parts of the world.

$C$-glass. Known as chemical glass, C-glass has a very good resistance to chemical impact

E-glass. Along with the characteristics of C-glass, E-glass has a with very good insulation to electricity

$A E$-glass. AE-glass provides a good resistance to Alkali.

$S$ glass. Known as structural glass and has good mechanical properties.

\subsubsection{Properties of Fibreglass}

Mechanical strength: The fresh and thin fibres are the strongest as the thinner fibres are more ductile.

Electrical characteristics. Fibre glass is a good electrical insulator.

Incombustibility. Being a mineral material, fibre glass is naturally incombustible. Neither it propagates nor supports a flame. It does not emit smoke or toxic products when exposed to heat. 
Dimensional stability: Having low coefficient of linear expansion, fibreglass is not much sensitive to variations in temperature and humidity.

Compatibility with organic matrices. Fibreglass has an ability of combining with many synthetic resins and certain mineral matrices like cement.

Non-rotting. Fibreglass remains unaffected by rodents and insects.

Thermal conductivity. The thermal conductivity of glass fibre is low which makes useful in the building industry.

Dielectric permeability. This property of fibreglass makes use in electromagnetic windows.

\subsubsection{Application}

Beverage industry. In the industry fibre glass grating makes its use in bottling lines.

Car washes. Fibre glass grating helps in providing contrast to the colour of car which was previously forbidden.

Chemical industry. As glass fibers are chemical resistant, they are used in the industry to have safety features.

Cooling towers: Glass fibres are used for protection against corrosion as well as as screenings for keeping people and animals away from danger zones.

Docks and marinas: As Fibre glass are resistant to corrosion, they are used here for protection.

\subsection{Optical Fibres}

An optical fibre is slightly thicker than human hair and it is manufactured by drawing glass or plastic. Glass optical fibres are mostly made from silica, but other materials such as fluorozirconate, fluoroaluminate, and chalcogenide glasses and also crystalline materials like sapphire, are used for longer-wavelength infrared or other specialized applications. These fibres are mainly used for transmitting light to longer distances without undergoing much losses and work on the principle of total internal reflection [45].

\subsubsection{Types of Optical Fibre}

\section{Single mode}

Single Mode cable is a single stand with a single transmission mode of 8.3 to 10 micron glass fibre.

\section{Multimode}

Multi-Mode cable has a slightly larger diameter, with a typical diameter in the 50-to-100 micron range for the light carrying part.

Plastic optical fibre (POF)

POF is a new plastic-based cable that promises a quality comparable to glass cable on very short runs, but at a lower cost.

\subsubsection{Application of Optical Fibres}

\section{In telecommunication field}

Many telecommunication industries use optical fibres in order to transmit 
telephone communication signals, internet signals, cable television signals, etc as they are having lower attenuation and interference.

In space application

Fibre optics offer many advantages over conventional satellite communications wire systems, including low weight, high bandwidth capacity, simple data bussing architecture, invulnerability of electromagnetic interference (EMI) and cost-effectiveness.

\section{Mining applications}

Mining industries are using optical fibres for better communication and improving monitoring standards in order to improve safety standards.

\section{Military application}

Tele-operated weapons systems were designed to provide the soldier with unparalleled communication, operator standoff capability, non-line-of-sight targeting, precise kill capability. The government/industry team has worked hard to develop a reliable fibre optic dispenser design that is part of the data transmission link between a launch platform and a weapon [46].

\section{Medical application}

Many surgical systems rely on optical fibres. Due to unique properties of fused silica, laser light can be efficiently transported into the body. In addition, optical fibres give flexibility to reach areas of the human body that are otherwise difficult to access [47].

\subsection{Aramid Fibres}

Aramid fibres are a class of synthetic fibres that are heat-resistant and strong. They are used for ballistic-rated body armor fabric and ballistic composites in aerospace and military applications, in bicycle tires, marine cordage, marine hull reinforcement, and as a substitute for asbestos. The fibre chain molecules are highly oriented along the axis of the fibre. Therefore, more of the chemical bond leads to fibre durability than many other synthetic fibres [48]. Aramides have a very high point of melting $\left(>500^{\circ} \mathrm{C}\right)$.

\section{Characterstic of Aramid fibre}

Aramids have a high degree of orientation with other fibres such as high molecular weight polyethylene, a characteristic that dominates their properties. General chracteristics includegood resistance to abrasion, good resistance to organic solvents, nonconductive, low flammability, good fabric integrity at elevated temperatures, very high melting point $\left(>500^{\circ} \mathrm{C}\right)$, sensitive to acids and salts, sensitive to ultraviolet radiation [49].

Para-aramids

para-aramid fibres, Twaron and Kevlar, provide outstanding strength-to-weight properties:-high Chord, modulus high tenacity, low creep, difficult to die [50].

\subsection{Natural Fibre}

Fibres that are produced by plants, animals, and geological processes. They can be used as a component of composite materials, where the orientation of fibres 
impacts the properties. Natural fibres can also be matted into sheets to make paper or felt.

The earliest evidence of humans using fibres is the discovery of wool and dyed flax fibres found in a prehistoric cave in the Republic of Georgia that date back to $36,000 \mathrm{BP}$. In high-tech applications natural fibre can be used, such as composite parts for automobiles [51]. Compared to composites reinforced with glass fibres, composites with natural fibres have advantages such as lower density, better thermal insulation, and reduced skin irritation. Further, natural fibres can be broken down by bacteria once they are no longer in use, which is not possible with glass fibre [52] [53].

Natural fibres can be used as good sweat absorbents and can be found in a many variety of textures. Cotton fibres made from the cotton plant, for example, produce fabrics that are light in weight, soft and smooth in texture, and which can be made in various colors and sizes. Clothes made from natural fibres such as cotton fibre is preferred over synthetic fibre in hot and humid climates [54].

\section{Coating on Fibres}

\subsection{Carbon Fibre}

\section{Electrophoretic method}

The adhesion of GO and CF is so weak that GO can easily fall off the surface of the fibre. To solve this problem, an easy way to prepare graphene oxide/carbon fibre hybrid fibre from oxidative treatments combined with electrophoretic deposition is therefore proposed [55]. Treatment with hydrogen peroxide and concentrated nitric acid combined with electrophoretic deposition process can effectively prepare a coating of graphene oxide on carbon fibre.

Carbon fibre towing can be used as a deposition electrode for GO EPD and as a counter electrode, two stainless steel plates can be mounted opposite $\mathrm{CF}$. $\mathrm{PH}=$ 10 is used as a GO aqueous dispersion EPD state and the GO concentration used is $0.25 \mathrm{~g} / \mathrm{L}$, the $\mathrm{pH} 10.0$ aqueous solution is achieved by applying a solution of $0.1 \mathrm{M}$ sodium hydroxide [56]. Ultrasonic GO aqueous dispersion is prepared $1 \mathrm{~h}$ before the EPD process. The EPD process is then carried out for $20 \mathrm{~min}$ at constant voltages of $20 \mathrm{~V}$, with a distance of $2 \mathrm{~cm}$ between the electrodes. The CF tow is wound on a roll after the EPD process [57].

\section{Dip coating}

CFs were immersed directly in a stable $\mathrm{GnP}$ suspension and the coating conditions were optimized to achieve a high homogeneous and well-dispersed GnP density. The non-coated and UV-ozone-treated CFs were unwound with the use of mirror-finished stainless steel rollers, and passed through the coating solution. To ensure a homogeneous fibre coating, the tow was spread as much as possible. The CF tow's feeding speed was $0.3 \mathrm{~m} / \mathrm{min}$ [58]. Following immersion, the fibres were dried in two tower-shaped furnaces by successive heat exposure. The temperature inside the furnaces was set at $125^{\circ} \mathrm{C}$ and the total fibre residence time in the furnaces was approximately $6.5 \mathrm{~min}$. The fibres were then 
woven onto an inoxidable steel mandrel that was moved to an oven set at $60^{\circ} \mathrm{C}$ for $3 \mathrm{~h}$ to eliminate any residual NMP [59].

\section{Spray coating}

Graphene nanoplate solution of $2 \mathrm{mg} / \mathrm{ml}$ is prepared in acetone and ultrasonicated for $40 \mathrm{~min}$. After this, the homogeneous graphene dispersion of $50 \mathrm{ml}$ is spray-coated on carbon fibre veil by a portable commercial spray gun. The spraying pressure can be taken as $0.2 \mathrm{MPa}$, the flow rate of the graphene dispersion solution out of the spraying nozzle can be $1 \mathrm{~mL} / \mathrm{cm}^{2}$. The carbon fibre veil with coated graphene is then dried at room temperature for $24 \mathrm{~h}$ [60].

Chemical Vapour Deposition

Graphene oxide (GO) is introduced to the surface of CFs by chemical vapor deposition (CVD) to improve the mechanical properties without sacrificing fibre tensile strength. The deposition of thermal chemical vapor produces graphene oxide on the CF substrate. First, CFs are fixed to the graphite frame and the tension is adjusted through the tensiometer at both ends of the CFs to $10 \mathrm{~N}$ [61]. The GO is ultrasonically dispersed in ethanol solution for $2 \mathrm{~h}$ and then combined with epoxy resin. The excess ethanol from a mixture of GO-epoxy is removed by keeping the mixture in the oven at $60^{\circ} \mathrm{C}$ [62]. Mixture is subsequently stirred at $50^{\circ} \mathrm{C}$ for $24 \mathrm{~h}$ to obtain a homogeneous mixture. The graphite frame is then placed in the single-zone atmospheric quartz tube furnace with a $60-\mathrm{cm}$ long heating zone and a constant flow of $1000 \mathrm{sccm}$ nitrogen atmosphere is inserted into the quartz tube for $10 \mathrm{~min}$ to exhaust the air [63]. The temperature of the reactor then rises to $1000^{\circ} \mathrm{C}$ at a heating rate of $10^{\circ} \mathrm{C} / \mathrm{min}$ and ethanol is then pumped through a peristaltic pump into the reactor to produce graphene oxide on the $\mathrm{CF}$ at a flow rate of $20 \mathrm{~mL} / \mathrm{h}$. Nitrogen is used as a carrier during the deposition process with a flow rate of $400 \mathrm{sccm}$. After the reaction, the furnace in liquid nitrogen is cooled to room temperature [63].

\subsection{Glass Fibre}

\section{Electrophoretic deposition}

To create a stable suspension of Graphene Oxide (GO) water is used as a solvent. The concentration of GO in water can be taken as $1 \mathrm{mg} / \mathrm{ml}$ and the dispersion is left for sonication for 1 hour. Glass Fibres (GF) are non-conductive in nature as a result to perform the coating process two copper electrodes are used in electrophoretic deposition technique. The GF is kept near the anode [64]. As GO display negative potential due functionalities attached during oxidation reaction, when the process begins GO begins to move towards the anode and get deposited on GF. This process can be carried out at various applied voltages up to $10 \mathrm{~V} / \mathrm{cm}$ with a deposition time of $5 \mathrm{~min}$ and electrode gap of $2 \mathrm{~cm}$ [64] [65]. The obtained sample can be dried at $40^{\circ} \mathrm{C}$ in vacuum oven for $12 \mathrm{~h}$ [65].

Hand lay-up method

In this method GO is dispersed in epoxy resin first. The GO and epoxy resin mixture is then applied on GF. The layers of coated GF are then joined layer by layer to form composite. The epoxy resin is mixed with $10 \%$ hardener. After 
creating the laminate it is hot press compressed for $20 \mathrm{~min}$ at a temperature of $60^{\circ} \mathrm{C}$ and under a pressure of $10 \mathrm{~kg} / \mathrm{cm}^{2}[66]$.

\section{Sol-gel and dip-coating method}

Graphene oxide is prepared by using modified hummers method. The solution is diluted with distilled water and $20 \mathrm{ml} \mathrm{H}_{2} \mathrm{O}_{2}$ is added to stop the reaction in hummers method. The suspension obtained is centrifuged and washed with $10 \% \mathrm{HCl}$ and distilled water repeatedly. Uniformly dispersed Graphene Oxide suspension is prepared. To this suspension hydrazine hydrate which is a reducing agent is added in a volume fraction of $0.5 \%$, and then heated at $50^{\circ} \mathrm{C}$ for $1 \mathrm{~h}$ without stirring [67]. Because of the treatment given to the suspension, the Graphene Oxide partially reduces into reduced Graphene Oxide resulting in the formation of graphene hydrosol. Glass Fibres are then dipped and coating of hydrosol is produced [68]. For further reduction of the reduced graphene oxide and excess of hydrazine hydrate and water, the coated fibres are made to dry in an oven at $120^{\circ} \mathrm{C}$ for $30 \mathrm{~min}$. As a result, a firm coating of reduced graphene oxide is produced [68].

\section{Covalently grafting GO sheets on GFs}

GO is prepared by making use of modified Hummers method. In this method of producing coating GFs surface is modified by silane coupling agent with amino group. Finally, GO was covalently grafted onto GFs by amidation reaction between the carboxygroups of GO and the amino groups of amino-terminated GFs [69].

Spin coating of graphene on glass fibre

Graphene in powder form is dissolved in water with a concentration of 15 $\mathrm{mg} / \mathrm{ml}$ and the resulting solution is coated onto the glass substrates by spin coating method. The glass substrates are preheated at $200^{\circ} \mathrm{C}$. The heated glass fibre with the graphene solution is allowed to stand for $5 \mathrm{~s}$ and then spin at 500 $1000 \mathrm{rpm}$ for $10 \mathrm{~s}$ and $5000 \mathrm{rpm}$ for $30 \mathrm{~s}$ [70]. After this, the graphene films are made to dry at $80^{\circ} \mathrm{C}$ inside a nitrogen filled glove box. In order to reduce Graphene oxide film on glass substrates into graphene films, hydrazine treatment along with annealing at $400^{\circ} \mathrm{C}, 800^{\circ} \mathrm{C}$ and $1000^{\circ} \mathrm{C}$ under argon flow is done [71]. A change of colour from brown to gray of the film is noticed, indicating the formation of grapheme.

\subsection{Optical Fibre}

\section{Drop casting method}

Graphene and GO are deposited on tapered optical fibre using drop casting technique. Graphene and GO are drop casted after making their suspension in water with concentration of $1 \mathrm{mg} / \mathrm{ml}$. After this, tapered optical fibre are made to anneal at $70^{\circ} \mathrm{C}$ for $1 \mathrm{~h}$ and left for one day so that thin film on the surface can be formed [72].

\section{Reduced Graphene Oxide onto D-Shaped Optical Fibres}

The GO is dispersed in water and ultra-sonication is done so that GO is properly dispersed. A concentration of $2.5 \mathrm{mg} / \mathrm{ml}$ of the resulting mixture is pre- 
pared. Next, the GO dispersion is made to deposit onto electro-polished aluminum substrates by spin-coating method and then it is covered by $300 \mathrm{~nm}$ thick-layer of polymethyl-methacrylate (PMMA) [73] By etching the substrate with an acid solution and washing it by deionized water, the films are transferred to the polished surface of D-shaped optical fibre by wet transfer method.

\subsection{Aramid Fibre}

The Arabic fibre is immersed acetone to get rid of its sizing for 24 hours. It is then dried under vacuum condition for 6 hours and at $40^{\circ} \mathrm{C}$. Then $2 \mathrm{~mm}$ long size of arabicfibre is added in a buffer solution for surface modification [74]. Next the dopamine is added to above mixture and was sonicated for $10 \mathrm{~min}$ and stirring was done constantly for 24 hours at room temperature. Polymerized polydopamine (PDA) was grafted on the on the newly sized arabicfibre surface by soaking it into doapamine solution. Now this PDA grafted aramid fibre was washed with deionized water to remove the residual of dopamine and PDA [75]. Then this filtered is dried at $40^{\circ} \mathrm{C}$ for 24 hours in vacuum condition. The modified aramid fibre of $\mathrm{GO} /$ dopamine can be obtain when PDA grafted aramid is immersed into GO solution upto $50^{\circ} \mathrm{C}$ for 12 to 24 hours under a vacuum condition so that it react through amine-catechol. This newly modified aramid fibre is dried at $50^{\circ} \mathrm{C}$ for at least $24 \mathrm{~h}$ under a vacuum condition [75].

\subsection{Natural Fibres}

\subsubsection{Carauafibre}

The carauafibres is first cleaned by brushing and then it is washed and passed through drying stages. This fibres is then added in GO solution which is 0.56 $\mathrm{mg} / \mathrm{ml}$ of the weight corresponding to the $0.1 \%$ of carauafibre [76]. It is briskly stirred using a mechanical shaker for around 30 minutes. Thus a carauafibre soaked with GO is obtained. It is heated in oven for at least 24 hours for about $80^{\circ} \mathrm{C}$ thus obtaining a GO-carauafibre [76].

\subsubsection{Coir Fibre}

The coconut husk is dried under sun. This husk is then soaked in hot water and dried at $40^{\circ} \mathrm{C}$ so that it loose the interaction between lignocellulosic matrix and fibre. $1 \mathrm{~g}$ of cetyltrimethyl ammonium bromide (CTAB) which is a cationic surfactant is added to $100 \mathrm{ml}$ of methanol. Then $2 \mathrm{~g}$ of GO powder is added to the mixture. Ultrasonification of this mixture is done for 3 hours using bath sonicator [77]. Then solution is briskly stirred for proper and continuous mixing after addition of $200 \mathrm{~g}$ of epoxy resin. Further mixture is kept in oven at temperature of around $50^{\circ} \mathrm{C}$ for complete removal of methanol and then it is brought down to its room temperature [77] [78]. Next $10 \mathrm{~g}$ of coir fibre was immersed in the mixture using glass rod for 1 hour and later on it is mixed with hardener in ratio of 10:1. The hand layup technique is used for spreading the mixture on the substrate. A mould releasing agent used here is polyvinyl alcohol (PVA) which is thin film of $5 \%$ aqueous solution. Then the mould is closed with its core and 
curing is done for a week at $1 \mathrm{~atm}$ pressure and room pressure. Then this cured composite was taken out and the epoxy/coir fibre composite with graphene oxide is obtained [78].

\subsubsection{Hemp Fibre}

The Graphene employed in this work were of industrial grade with a purity of 95 wt $\%$. To produce modified composites varying concentration of $0.1 \%-0.5 \%$ in the incremental steps of $0.1 \%$ by the weight $\%$ of the epoxy matrix were used. Resin and Hardener were selected in the stochiometric ratio of 90:10 to produce specimen under study. Dispersion of graphene and hemp in epoxy was done using sonication method [79]. For further dispersion of Graphene and Hemp 3-roll shear mixing process was used and the mixture was mixed mechanically [79]. Do mechanical mixing untill solution become homogenoues. During mechanical mixing gas bubbles gets trapped, and are removed using degasification process. The mixture is cured at $600^{\circ} \mathrm{C}$ for 2 hours followed by $1000^{\circ} \mathrm{C}$ for 4 hours. The blend of resin and hardener was then poured into an aluminum mould of size $260 \mathrm{~mm} \times 225 \mathrm{~mm} \times 5 \mathrm{~mm}$ to produce laminates [79] [80].

For alkaline treatment raw hemp was taken and thoroughly cleaned. The cleaned hemp was then cut in to 5 to $8 \mathrm{~mm}$ length manually. The Concentration of $5 \%$ of $\mathrm{NaOH}$ which gives maximum strength was prepared and the hemp fibres were made to soak in it for 2 hours [80]. The then treated hemp was neutralized with acetic acid until $\mathrm{pH}$ was 7 which was tested with the help of a universal indicator. Wash solution 3 times [81]. This would conclude the alkaline treatment. For permanganate treatment hemp was treated with $\mathrm{KMnO}_{4}$ for half an hour and washed again. The fibres were wrung and dried in the hot air oven at $333 \mathrm{~K}$ for 24 hours [81] [82]. The moulds were prepared and the samples of $3 \%, 5 \%$, and $7 \%$ by weight was prepared of both $\mathrm{KMnO}_{4}$ and $\mathrm{NaOH}$ treated Hemp by hand lay-up method. The hemp was taken in a beaker with graphene and epoxy and sonicated for 50 minutes [81] [82]. It was then poured into the mould and remained to settle for 24 hours, this would end the permanganate treatment of the hemp [82].

\subsection{Cotton Fibre}

$2 \mathrm{mg} / \mathrm{mL}$ GO solution with dispersed GO sheets in aqueous solution was prepared. Subsequently, the degreasing cotton usually applied in laboratory is cut into small pieces and immersed in the GO solution for $12 \mathrm{~h}$. The cotton pieces immersed in $\mathrm{GO}$ solution are then annealed in furnace at $250^{\circ} \mathrm{C}$ for $5 \mathrm{~h}$, under nitrogen protection. Therefore we get Grephene coated cotton fibre [83].

\section{Conclusions}

Graphene shows various outstanding features from many published results of the characterisation. Graphene-based materials can be used in a broad range of possible applications, including flexible, transparent electrodes, sensors and electronics. The nanocomposites based on graphene also show very low electrical 
conductivity percolation thresholds with improved mechanical, thermal and barrier properties. Nevertheless, the journey towards mature graphene use still faces several challenges. Flawless graphene is the perfect material for all types of applications, but the manufacturing techniques are not yet mature.

When pure, graphene-based materials and composites derived on a substratum were coated, potential electrical properties, barrier features, mechanical features and thermal characteristics were established. Certain characteristics such as catalytic activity, sensory tolerance and barrier efficiency were also established. Most of the papers published concentrate on electrical properties when graphene is used in coatings. Much more must be done to fully understand the possible applications of graphene-based coatings. The effect on quality should also be studied by the influence of graphene-coated surface morphology. No matter how the graphene is synthesized, the ease for subsequent coating processing needs to be considered.

\section{Conflicts of Interest}

The authors declare no conflicts of interest regarding the publication of this paper.

\section{References}

[1] Thomas, H., Herwig, P. and Kromp, K. (1995) Coating of Carbon Fibre-Strength of Fibre. Journal of American Ceramic Society, 78, 133-136. https://doi.org/10.1111/j.1151-2916.1995.tb08372.x

[2] Zhang, X.Q., et al. (2012) Interfacial Microstructure and Properties of Carbon Fibre Composites Modified with Graphene Oxide. ACS Applied Materials \& Interfaces, 4 , 1543-1552.

[3] Li, C.Q., Wang, X.L., Xu, L.H., Gao, A.J. and Xu, D.H. (2019) Preparation of Graphene Oxide/Polyacrylonitrile Fibre from Graphene Oxide Solution with High Dispersivity. Composite Interfaces, 27, 177-190.

[4] Li, F., Liu, Y., Qu, C.-B., Xiao, H.-M., Hua, Y., Sui, G.-X. and Fu, S.-Y. (2015) Enhanced Mechanical Properties of Short Carbon Fibre Reinforced Polyethersulfone Composites by Graphene Oxide Coating. Polymer Journal, 59, 155-165. https://doi.org/10.1016/j.polymer.2014.12.067

[5] Dong, J.D., Jia, C.Y., Song, Y.J., He, J.M. and Huang, Y.D. (2017) Improved Interfacial Properties of Carbon Fibre-Reinforced Epoxy Composites with $\mathrm{Fe}_{2} \mathrm{O}_{3} / \mathrm{Graphene}$ Nanosheets Using a Magnetic Field. Journal of Adhesion Science and Technology, 32, 1018-1026. https://doi.org/10.1080/01694243.2017.1398852

[6] Liu, Y.D. and Kumar, S. (2013) Recent Progress in Fabrication, Structure, and Properties of Carbon Fibres. Polymer Journal Review, 52, 234-258.

https://doi.org/10.1080/15583724.2012.705410

[7] Kumari, N. and Kumar, K. (2018) Mechanical Behaviour of Graphene and Carbon Fibre Reinforced Epoxy Based Hybrid Nanocomposites for Orthotic Calipers. Jour nal of Experimental Nanoscience, 13, S14-S23. https://doi.org/10.1080/17458080.2018.1431847

[8] Chen, S., Shen, B. and Sun, F. (2017) The Influence of Normal Load on the Tribological Performance of Electrophoretic Deposition Prepared Graphene Coating on 
Microcrystalline Diamond Surface. Diamond and Related Materials, 76, 50-57. https://doi.org/10.1016/j.diamond.2017.04.008

[9] Li, G., Shrotriya, V., Huang, J.S., Yao, Y., Moriarty, T., Emery, K., et al. (2015) High-Efficiency Solution Processable Polymer Photovoltaic Cells by Self-Organization of Polymer Blends. Nature Materials, 4, 864-868.

[10] Qiu, J., Zhang, C., Wang, B. and Liang, R. (2007) Carbon Nanotube Integrated Multifunctional Multiscale Composites. Nanotechnology, 18, Article ID: 275708. https://doi.org/10.1088/0957-4484/18/27/275708

[11] Eda, G., Lin, Y.Y., Miller, S., Chen, C.W., Su, W.F. and Chhowalla, M. (2008) Transparent and Conducting Electrodes for Organic Electronics from Reduced Graphene Oxide. Applied Physics Letters, 92, Article ID: 233305.

https://doi.org/10.1063/1.2937846

[12] Feng, J., Wang, X., Tian, Y., Bu, Y., Luo, C. and Sun, M. (2017) Electrophoretic Deposition of Graphene Oxide onto Carbon Fibres for In-Tube Solid-Phase Microextraction. Journal of Chromatography A, 1517, 209-214. https://doi.org/10.1016/j.chroma.2017.07.086

[13] Botas, C., Álvarez, P., Blanco, P., Granda, M., Blanco, C., Santamaría, R., Romasanta, L.J., Verdejo, R., López-Manchado, M.A. and Menéndez, R. (2013) Graphene Materials with Different Structures Prepared from the Same Graphite by the Hummers and Brodie Methods. Carbon, 65, 156-164. https://doi.org/10.1016/j.carbon.2013.08.009

[14] Su, Q., Pang, S., Alijani, V., Li, C., Feng, X. and Mullen, K. (2009) Composites of Graphene with Large Aromatic Molecules. Advanced Materials, 21, 3191-3195. https://doi.org/10.1002/adma.200803808

[15] Mahmood, H., Tripathi, M., Pugno, N. and Pegoretti, A. (2016) Enhancement of Interfacial Adhesion in Glass Fibre/Epoxy Composites by Electrophoretic Deposition of Graphene Oxide on Glass Fibres. Composites Science and Technology, 126, 149-157. https://doi.org/10.1016/j.compscitech.2016.02.016

[16] Varshney, P., Deepa, M., Sharma, N. and Agnihotry, S.A. (2002) Transmission Enhancement in Tin Oxide Conductive Coatings for ECWs. Solid State Ionics, 152, 877-881. https://doi.org/10.1016/S0167-2738(02)00389-2

[17] Srivastava, S., Kumar, V., Ali, M.A., Solanki, P.R., Srivastava, A., Sumana, G., Saxena, P.S., Joshi, A.G. and Malhotra, B.D. (2013) Electrophoretically Deposited Reduced Graphene Oxide Platform for Food Toxin Detection. Nanoscale, 5, $3043-$ 3051. https://doi.org/10.1039/c3nr32242d

[18] Sánchez-Campo, M., Jiménez-Suárez, A. and Ureña, A. (2013) Effect of the Carbon Nanotube Functionalization on Flexural Properties of Multiscale Carbon Fibre/ Epoxy Composites Manufactured by VARIM. Composites Part B, 45, 1613-1619. https://doi.org/10.1016/j.compositesb.2012.09.063

[19] Novoselov, K.S., Geim, A.K., Morozov, S.V., Jiang, D., Zhang, Y., Dubonos, S.V., et al. (2004) Electric Field Effect in Atomically Thin Carbon Films. Science, 306, 666-669. https://doi.org/10.1126/science.1102896

[20] Bolotin, K.I., Sikes, K.J., Jiang, Z., Klima, M., Fudenberg, G., Hone, J., Kim, P. and Stormer, H.L. (2008) Ultrahigh Electron Mobility in Suspended Graphene. Solid State Communications, 146, 351-355. https://doi.org/10.1016/j.ssc.2008.02.024

[21] Kenry, Lee, W.C., Loh, K.P., et al. (2018) When Stem Cells Meet Graphene: Opportunities and Challenges in Regenerative Medicine. Biomaterials, 155, 236-250. https://doi.org/10.1016/j.biomaterials.2017.10.004

[22] Mikolajick, T., Salinga, M., Kund, M. and Kever, T. (2009) Nonvolatile Memory 
Concepts Based on Resistive Switching in Inorganic Materials. Advanced Engineering Materials, 11, 235-240. https://doi.org/10.1002/adem.200800294

[23] Ku, S.H., Lee, M. and Park, C.B. (2013) Carbon-Based Nanomaterials for Tissue Engineering. Advanced Healthcare Materials, 2, 244-260.

https://doi.org/10.1002/adhm.201200307

[24] Stout, D.A. and Webster, T.J. (2012) Carbon Nanotubes for Stem Cell Control. Mater Today, 15, 312-318. https://doi.org/10.1016/S1369-7021(12)70136-0

[25] Moser, J., Barreiro, A. and Bachtold, A. (2007) Current-Induced Cleaning of Graphene. Applied Physics Letters, 91, Article ID: 163513.

https://doi.org/10.1063/1.2789673

[26] He, C.L., Zhuge, F., Zhou, X.F., Li, M., Zhou, G.C., Liu, Y.W., Wang, J.Z., Chen, B., Su, W.J., Liu, Z.P., Wu, Y.H., Cui, P. and Li, R.-W. (2009) Nonvolatile Resistive Switching in Graphene Oxide Thin Films. Applied Physics Letters, 95, 232. https://doi.org/10.1063/1.3271177

[27] Balandin, A.A., Ghosh, S., Bao, W., Calizo, I., Teweldebrhan, D., Miao, F., et al. (2008) Superior Thermal Conductivity of Single-Layer Graphene. Nano Letters, 8, 902-907. https://doi.org/10.1021/nl0731872

[28] Jiang, J.J., et al. (2016) Preparation of Graphene Oxide Coatings onto Carbon Fibres by Electrophoretic Deposition for Enhancing Interfacial Strength in Carbon Fibre Composites. Journal of the Electrochemical Society, 163, D133-D139. https://doi.org/10.1149/2.0571605jes

[29] Qin, W.Z., et al. (2014) Mechanical and Electrical Properties of Carbon Fibre Composites with Incorporation of Graphene Nanoplatelets at the Fibre-Matrix Interphase. Composites Part B: Engineering, 69, 335-341.

[30] Vázquez-Moreno, J.M., Sánchez-Hidalgo, R., Sanz-Horcajo, E., Viña, J., Verdejo, R. and López-Manchado, M.A. (2019) Preparation and Mechanical Properties of Graphene/Carbon Fibre-Reinforced Hierarchical Polymer Composites. Journal of Composites Science, 3, 30. https://doi.org/10.3390/jcs3010030

[31] He, R.Q., Chang, Q.X., Huang, X.J. and Bo, J. (2018) Improved Mechanical Properties of Carbon Fibre Reinforced PTFE Composites by Growing Grapheme Oxide on Carbon Fibre Surface. Composite Interfaces, 25, 995-1004.

[32] Li, X., Zhu, Y., Cai, W., Borysiak, M., Han, B., Chen, D., Piner, R.D., Colombo, L. and Ruoff, R.S. (2009) Transfer of Large-Area Graphene Films for High-Performance Transparent Conductive Electrodes. Nano Letters, 9, 4359. https://doi.org/10.1021/nl902623y

[33] Mo, X., Wei, Y., Zhang, X., et al. (2016) Enhanced Stem Cell Osteogenic Differentiation by Bioactive Glass Functionalized Graphene Oxide Substrates. Journal of Nanomaterials, 2016, Article ID: 5613980. https://doi.org/10.1155/2016/5613980

[34] Sugiyama, K., Ishii, H., Ouchi, Y. and Seki, K. (2000) Dependence of Indium-Tinoxide Work Function on Surface Cleaning Method as Studied by Ultraviolet and X-Ray Photoemission Spectroscopies. Journal of Applied Physics, 87, 295-298. https://doi.org/10.1063/1.371859

[35] Blake, P., Brimicombe, P.D., Nair, R.R., Booth, T.J., Jiang, D., Schedin, F., et al. (2008) Graphene-Based Liquid Crystal Device. Nano Letters, 8, 1704-1708. https://doi.org/10.1021/nl080649i

[36] Boehm, H.P., Setton, R. and Stumpp, E. (1986) Nomenclature and Terminology of Graphite Intercalation Compounds. Carbon, 24, 241-245. https://doi.org/10.1016/0008-6223(86)90126-0

[37] Vanbommel, A.J., Crombeen, J.E. and Vantooren, A. (1975) LEED and Auger Elec- 
tron Observations of the $\mathrm{SiC}(0001)$ Surface. Surface Science, 48, 463-472. https://doi.org/10.1016/0039-6028(75)90419-7

[38] Mueller, S.M. and Glowacki, J. (2001) Age-Related Decline in the Osteogenic Potential of Human Bone Marrow Cells Cultured in Three-Dimensional Collagen Sponges. Journal of Cellular Biochemistry, 82, 583-590. https://doi.org/10.1002/jcb.1174

[39] Butler, M.A. (1977) Photoelectrolysis and Physical Properties of the Semiconducting Electrode WO3. Journal of Applied Physics, 48, 1914-1920. https://doi.org/10.1063/1.323948

[40] Dimitrakakis, G.K., Tylianakis, E. and Froudakis, G.E. (2008) Pillared Graphene: A New 3-D Network Nanostructure for Enhanced Hydrogen Storage. Nano Letters, 8 , 3166-3170. https://doi.org/10.1021/nl801417w

[41] Mahmood, H., Vanzetti, L., Bersani, M. and Pegoretti, A. (2018) Mechanical Properties and Strain Monitoring of Glass-Epoxy Composites with Graphene-Coated Fibres. Composites: Part A, 107, 112-123. https://doi.org/10.1016/j.compositesa.2017.12.023

[42] Fang, M.H., Xiong, X.H., Hao, Y.B., Zhang, T.X., Wang, H., Cheng, H.-M. and Zeng, Y. (2019) Preparation of Highly Conductive Graphene-Coated Glass Fibres by Sol-Gel and Dip-Coating Method. Journal of Materials Science \& Technology, 35, 1989-1995. https://doi.org/10.1016/j.jmst.2019.05.027

[43] Chen, J., Zhao, D., Jin, X., Wang, C.C., Wang, D.Z. and Ge, H.Y. (2014) Modifying Glass Fibres with Graphene Oxide: Towards High-Performance Polymer Composites. Composites Science and Technology, 97, 41-45. https://doi.org/10.1016/j.compscitech.2014.03.023

[44] Kymakis, E., Stratakis, E., Stylianakis, M.M., Koudoumas, E. and Fotakis, C. (2011) Spin Coated Graphene Films as the Transparent Electrode in Organic Photovoltaic Devices. Thin Solid Films, 520, 1238-1241. https://doi.org/10.1016/j.tsf.2011.04.208

[45] Girei, S.H., Shabaneh, A.A., Ngee-Lim, H., Hamidon, M.N., Mahdi, M.A. and Yaacob, M.H. (2015) Tapered Optical Fibre Coated with Graphene Based Nanomaterials for Measurement of Ethanol Concentrations in Water. Optical Review, 22, 385-392. https://doi.org/10.1007/s10043-015-0075-8

[46] Zhang, X., Hirai, M., Cantero, S., et al. (2011) Isolation and Characterization of Mesenchymal Stem Cells from Human Umbilical Cord Blood: Reevaluation of Critical Factors for Successful Isolation and High Ability to Proliferate and Differentiate to Chondrocytes as Compared to Mesenchymal Stem Cells from Bone Marrow and Adipose Tissue. Journal of Cellular Biochemistry, 112, 1206-1218. https://doi.org/10.1002/jcb.23042

[47] Stankovich, S., Dikin, D.A., Piner, R.D., et al. (2007) Synthesis of Graphene-Based Nanosheets via Chemical Reduction of Exfoliated Graphite Oxide. Carbon, 45, 15581565. https://doi.org/10.1016/j.carbon.2007.02.034

[48] Mimeault, M., Hauke, R., Mehta, P.P., et al. (2007) Recent Advances in Cancer Stem/Progenitor Cell Research: Therapeutic Implications for Overcoming Resistance to the Most Aggressive Cancers. Journal of Cellular and Molecular Medicine, 11, 981-1011. https://doi.org/10.1111/j.1582-4934.2007.00088.x

[49] Jiao, L.Y., Zhang, L., Wang, X.R., Diankov, G. and Dai, H.J. (2009) Narrow Graphene Nanoribbons from Carbon Nanotubes. Nature, 458, 877-880. https://doi.org/10.1038/nature07919

[50] Zhang, Z., Shao, C., Li, X., et al. (2010) Electrospunnanofibres of p-Type NiO/ n-Type ZnO Heterojunctions with Enhanced Photocatalytic Activity. ACS Applied Materials \& Interfaces, 2, 2915-2923. https://doi.org/10.1021/am100618h 
[51] Stankovich, S., Dikin, D.A., Dommett, G.H.B., Kohlhaas, K.M., Zimney, E.J., Stach, E.A., Piner, R.D., Nguyen, S.T. and Ruoff, R.S. (2006) Graphene-Based Composite Materials. Nature, 442, 282-286. https://doi.org/10.1038/nature04969

[52] Nagamura-Inoue, T. and He, H. (2014) Umbilical Cord-Derived Mesenchymal Stem Cells: Their Advantages and Potential Clinical Utility. World Journal of Stem Cells, 6, 195-202. https://doi.org/10.4252/wjsc.v6.i2.195

[53] Baksh, D., Yao, R. and Tuan, R.S. (2007) Comparison of Proliferative and Multilineage Differentiation Potential of Human Mesenchymal Stem Cells Derived from Umbilical Cord and Bone Marrow. Stem Cells, 25, 1384-1392. https://doi.org/10.1634/stemcells.2006-0709

[54] Li, X.S., Cai, W.W., An, J.H., Kim, S., Nah, J., Yang, D.X., Piner, R., Velamakanni, A., Jung, I., Tutuc, E., Banerjee, S.K., Colombo, L. and Ruoff, R.S. (2009) Large-Area Synthesis of High-Quality and Uniform Graphene Films on Copper Foils. Science, 324, 1312-1314. https://doi.org/10.1126/science.1171245

[55] Williams, G., Seger, B. and Kamat, P.V. (2008) $\mathrm{TiO}_{2}-\mathrm{Graphene}$ Nanocomposites. UV-Assisted Photocatalytic Reduction of Graphene Oxide. ACS Nano, 2, 1487-1491. https://doi.org/10.1021/nn800251f

[56] Foroutan, T., Nazemi, N., Tavana, M., et al. (2018) Suspended Graphene Oxide Nanoparticle for Accelerated Multilayer Osteoblast Attachment. Journal of Biomedical Materials Research, 106, 293-303. https://doi.org/10.1002/jbm.a.36231

[57] Roy, H.V., Kallinger, C. and Sattler, K. (1998) Manipulation of Graphitic Sheets Using a Tunneling Microscope. Journal of Applied Physics, 83, 4695.

https://doi.org/10.1063/1.367257

[58] Steinberg, D., Gerosa, R.M., Pellicer, F.N., Domingues, S.H., Thoroh de Souza, E.A. and Saito, L.A.M. (2017) Sub-300 fs Mode-Locked Erbium Doped Fibre Laser Using Graphene Oxide and Reduced Graphene Oxide onto D-Shaped Optical Fibres. SBMO/ IEEE MTT-S International Microwave and Optoelectronics Conference (IMOC), Aguas de Lindoia, 27-30 Aug. 2017. https://doi.org/10.1109/IMOC.2017.8121086

[59] Wang, H., Vinodgopal, K. and Dai, G.P. (2018) Large-Area Synthesis and Growth Mechanism of Graphene by Chemical Vapor Deposition. In: Chemical Vapor Deposition for Nanotechnology, IntechOpen, London.

[60] Liang, X., Chang, A.S.P., Zhang, Y., Harteneck, B.D., Choo, H., Olynick, D.L. and Cabrini, S. (2008) Electrostatic Force Assisted Exfoliation of Prepatterned Few-Layer Graphenes into Device Sites. Nano Letters, 9, 467-472. https://doi.org/10.1021/nl803512z

[61] Grabowska, I., Streminska, W., Janczyk-Ilach, K., et al. (2013) Myogenic Potential of Mesenchymal Stem Cells-The Case of Adhesive Fraction of Human Umbilical Cord Blood Cells. Current Stem Cell Research \& Therapy, 8, 82-90. https://doi.org/10.2174/1574888X11308010010

[62] Behabtu, N., Lomeda, J.R., Green, M.J., Higginbotham, A.L., Sinitskii, A., Kosynkin, D.V., Tsentalovich, D., Parra-Vasquez, A.N.G., Schmidt, J., Kesselman, E., Cohen, Y., Talmon, Y., Tour, J.M. and Pasquali, M. (2010) Spontaneous High-Concentration Dispersions and Liquid Crystals of Grapheme. Nature Nanotechnology, 5, 406-411. https://doi.org/10.1038/nnano.2010.86

[63] Rollings, E., Gweon, G.-H., Zhou, S.Y., Mun, B.S., McChesney, J.L., Hussain, B.S., Fedorov, A.V., First, P.N., First, P.N., de Heer, W.A. and Lanzar, A. (2006) Synthesis and Characterization of Atomically Thin Graphite Films on a Silicon Carbide Substrate. Journal of Physics and Chemistry of Solids, 67, 2172-2177. https://doi.org/10.1016/j.jpcs.2006.05.010 
[64] Rao, C.N.R., Maitra, U. and Matte, H.S.S.R. (2013) Synthesis, Characterization, and Selected Properties of Graphene. In: Rao, C.N.R. and Sood, A.K., Eds., Graphene: Synthesis, Properties, and Phenomena, Wiley-VCH, Hoboken. https://doi.org/10.1002/9783527651122.ch1

[65] Gong, X.Y., Liu, Y.Y., Wang, Y.S., et al. (2019) Amino Graphene Oxide/Dopamine Modified Aramid Fibres: Preperation, Epoxy Nanocomposite and Property Analysis. Polymer, 168, 131-137. https://doi.org/10.1016/j.polymer.2019.02.021

[66] Park, J., Kim, B., Han, J., et al. (2015) Graphene Oxide Flakes as a Cellular Adhesive: Prevention of Reactive Oxygen Species Mediated Death of Implanted Cells for Cardiac Repair. ACS Nano, 9, 4987-4999. https://doi.org/10.1021/nn507149w

[67] Zhang, L.W., Fu, H.B. and Zhu, Y.F. (2008) Efficient $\mathrm{TiO}_{2}$ Photocatalysts from Surface Hybridization of $\mathrm{TiO}_{2}$ Particles with Graphite-Like Carbon. Advanced Functional Materials, 18, 2180-2189. https://doi.org/10.1002/adfm.200701478

[68] Park, S. and Ruoff, R.S. (2009) Chemical Methods for the Production of Graphenes. Nature Nanotech, 4, 217-224. https://doi.org/10.1038/nnano.2009.58

[69] Ulisses, O.C., Lucio Fabio, C.N., et al. (2019) Effect of Graphene Oxide Coating on Natural Fibre Composite for Multilayered Ballistic Armor. Polymer, 11, 1356.

[70] Nguang, S.Y., Wong, S.R., Law, J.S., et al. (2017) Enhancing Adsorption Property of Engelhard Titanosilicate-10 through Incorporation of Graphene Oxide. Microporous and Mesoporous Materials, 252, 125-139. https://doi.org/10.1016/j.micromeso.2017.06.007

[71] Heer, D.W.A., Berger, C., Wu, X., First, P.N., Conrad, E.H., Li, X., Li, T., Sprinkle, M., Hass, J., Sadowski, M.L., Potemski, M. and Martinez, G. (2007) Epitaxial Graphene. Solid State Communications, 143, 92-100. https://doi.org/10.1016/j.ssc.2007.04.023

[72] Preetam, S.B. and Satyendra, M. (2019) Enriched Mechanical Properties of Epoxy/ Coir Fibre Composites with Graphene Oxide. Research \& Development in Material Science, 10, RDMS.000749. https://doi.org/10.31031/RDMS.2019.10.000749

[73] Weaver, C.L. and Cui, X.T. (2015) Directed Neural Stem Cell Differentiation with a Functionalized Graphene Oxide Nanocomposite. Advanced Healthcare Materials, 4, 1408-1416. https://doi.org/10.1002/adhm.201500056

[74] Zhou, X., Zhang, J., Wu, H., Yang, H., Zhang, J. and Guo, S. (2011) Reducing Graphene Oxide via Hydroxylamine: A Simple and Efficient Route to Graphene. The Journal of Physical Chemistry C, 115, 11957-11961. https://doi.org/10.1021/jp202575j

[75] Kobayashi, T., Bando, M., Kimura, N., Shimizu, K., Kadono, K., Umezu, N., et al. (2013) Production of a 100-m-Long High-Quality Graphene Transparent Conductive Film by Roll-to-Roll Chemical Vapor Deposition and Transfer Process. Applied Physics Letters, 102, Article ID: 023112. https://doi.org/10.1063/1.4776707

[76] Park, J.K., Do, I.H., Askeland, P. and Drzal, L.T. (2008) Electrodeposition of Exfoliated Graphite Nanoplatelets onto Carbon Fibres and Properties of Their Epoxy Composites. Composites Science and Technology, 68, 1734-1741. https://doi.org/10.1016/j.compscitech.2008.02.002

[77] Molina-Valdovinos, S., et al. (2018) Low-Dimensional Thermoelectricity in Graphene: The Case of Gated Graphene Superlattices. Physica E: Low-Dimensional Systems and Nanostructures, 101, 188-196. https://doi.org/10.1016/j.physe.2018.03.005

[78] Geng, D., Wu, B., Guo, Y., et al. (2012) From the Cover: Uniform Hexagonal Graphene Flakes and Films Grown on Liquid Copper Surface. Proceedings of the Na- 
tional Academy of Sciences of the United States of America, 109, 7992-7996. https://doi.org/10.1073/pnas.1200339109

[79] Becerril, H.A., Mao, J., Liu, Z., Stoltenberg, R.M., Bao, Z. and Chen, Y. (2008) Evaluation of Solution-Processed Reduced Graphene Oxide Films as Transparent Conductors. ACS Nano, 3, 463-470. https://doi.org/10.1021/nn700375n

[80] Hallad, S.A., Banapurmath, N.R., Patil, V., Ajarekar, V.S., et al. (2018) Graphene Reinforced Natural Fiber Nanocomposites for Structural Applications. IOP Conference Series: Materials Science and Engineering, 376, Article ID: 012072. https://doi.org/10.1088/1757-899X/376/1/012072

[81] Gurunathan, S., Han, J.W., Eppakayala, V. and Kim, J.-H. (2013) Biocompatibility of Microbially Reduced Graphene Oxide in Primary Mouse Embryonic Fibroblast Cells. Colloids and Surfaces B: Biointerfaces, 105, 58-66. https://doi.org/10.1016/j.colsurfb.2012.12.036

[82] Li, P., Zhao, L.B., Jiang, Z.D., Yu, M.Z., Li, Z., Zhou, X.Y. and Zhao, Y.L. (2019) A Wearable and Sensitive Graphene-Cotton Based Pressure Sensor for Human Physiological Signals Monitoring. Scientific Report, 9, Article No. 14457.

[83] Yamada, T., Ishihara, M. and Hasegawa, M. (2013) Large Area Coating of Graphene at Low Temperature Using a Roll-to-Roll Microwave Plasma Chemical Vapor Deposition. Thin Solid Films, 532, 89-93. https://doi.org/10.1016/j.tsf.2012.12.102 